You could be reading the full-text of this article now...

- if you become a subscriber (I am a subscriber (2))

- if you purchase this article

If you have access to this article through your institution, you can view this article in OvidSP.

American Journal of Physical Medicine \& Rehabilitation:

December 2013 - Volume 92 - Issue 12 - p 1095-1103

doi: 10.1097/PHM.obo13e31829b49eb

Original Research Articles

\title{
Men Older than 50 Yrs Are More Likely to Fall than Women Under Similar Conditions of Health, Body Composition, and Balance
}

\author{
Pereira, Catarina L.N. PhD; Baptista, Fátima PhD; Infante, Paulo PhD
}

\section{Abstract}

Objective: The aim of this study was to analyze the contribution of sex to the occurrence of falls, accounting for comorbidities and differences in physical fitness.

Design: This was a cross-sectional study of 587 community-dwelling adults who were older than 50 yrs. Falls, comorbidities (number of diseases and physical impairments), and physical fitness (body composition, lower and upper body strength and flexibility, agility, aerobic endurance, and balance) were evaluated via questionnaires, bioimpedance, and Fullerton batteries, respectively.

Results: Compared with the men, the women presented a 10\% higher fall prevalence, 1.7 more diseases/impairments, $10 \%$ more body fat, $26 \%$ less lean body mass, and poorer physical capacity $(P<0.05)$. Multivariate logistic regression revealed that male sex (odds ratio [OR], 2.723; 95\% confidence interval [CI], 1.190-6.230) increased the likelihood of falling, after adjustment for comorbidities (OR, 1.213; 95\% CI, 1.109-1.328), lean mass (OR, 0.958; 95\% CI, 0.927-0.989), fat mass (OR, 1.053; 95\% CI, 1.021-1.086), and balance (OR, 0.942; 95\% CI, 0.914-0.971), which were the main risk factors of falls.

Conclusions: Women are more susceptible to falling, presumably because they have poorer health and physical fitness than do men. However, when the values for comorbidities, lean and fat body mass, and balance were similar, the men demonstrated a higher probability of falling. Age is not a significant risk factor of falls under favorable conditions of health, body composition, and balance.

Copyright (C) 2013 by Lippincott Williams \& Wilkins 